\title{
LXXXVIII. Some experiments on the magnetic field of two electromagnets in rotation
}

\section{S.J. Barnett}

To cite this article: S.J. Barnett (1913) LXXXVIII. Some experiments on the magnetic field of two electromagnets in rotation , Philosophical Magazine Series 6, 26:156, 987-991, DOI: $10.1080 / 14786441308635047$

To link to this article: http://dx.doi.org/10.1080/14786441308635047

曲 Published online: 08 Apr 2009.

Submit your article to this journal $\sqsubset$

Џ Article views: 3

Q View related articles $\square$

Citing articles: 1 View citing articles 5 


\section{[ 987 ]}

LXXXVIII. Some Experiments un the Magnetic Field of two Electromagnets in Rotation. By S. J. BARnetr, Professor of Physics in the Ohio State University*.

TN 1903 E. Hoppe † made some experiments with rotating magnets and iron filings which be thought conclusive in favour of the hypothesis that a magnet in rotation carries with it the lines of induction of its field. In these experiments a glass plate or a piece of paper was supported horizontal just above a vertical magnet, and iron filings were let fall upon the paper or glass while the magnet was rotated about a vertical line through its centre. Hoppe found that when the field was very intense, the iron filings became arranged in curves which were not radial, but were curved as if the rotating magnet dragged the lines of induction with it, the nearer parts ahead of the more remote. He fonnd also that the effect was increased by surrounding the upper pole of the magnet with an iron ring at a small distance. With this arrangement and an electromagnet with a round core $3 \cdot 2 \mathrm{~cm}$. in diameter, driven at a speed of 10 revolutions per second, he found that the lines at the edge of the magnet deviated from radial directions by as much as $2 \mathrm{~mm}$.

S. Valentiner $\ddagger$ repeated some of these experiments with a thin but strongly magnetized circular cylindrical magnet. When the magnet was rotated about its geometrical axis he did not get the effect observed by Hoppe ; but the effect uppeared when the magnet was rotated excentrically about a line parallel to its axis. Hence he concluded that Hoppe's results were due to unsymmetrical magnetization of his magnets and that his interpretation of them was incorrect.

There being available some apparatus which, though constructed primarily for another investigation $\S$, was capable, when slightly modified, of giving information on the problem examined by Hoppe and Valentiner of a much more exact character than could be obtained by their methods, I thought it worth while, a number of years ago, to make some experiments on the subject. These experiments have recently been repeated and extended under much more favourable conditions, again with apparatus mostly designed primarily for other work.

* Communicated by the Author.

+ Phys. Zeit. v. p. 650 (1904).

$\ddagger$ Phys. Zeit. vi. p. 10 (1905).

$\S$ Phys. Rev. xxxv.p. 323 (1912); Science, xxxvii. pp. 113, 560 (1913); Phys. Zeit. xiii. p. 803 (1912), and xiv. p. 251 (1913). 
For these experiments two similar cylindrical electromagnets were mounted with their axes in the same straight line, and were so magnetized that the lines of induction stretched across from one of the adjacent poles to the other. A small elongated cylinder of iron was so mounted at the point of the field under investigation as always to follow any change (of the sort under investigation) in the direction of the intensity at the point, and a mirror attached to the magnet's support and other optical appliances made it possible to determine any change in the magnet's orientation with great precision.

In the principal series of experiments the magnets were rotated in opposite directions, and the change in the direction of the intensity produced by reversing both rotations was observed. The apparatus as arranged for these experiments will be briefly described.

The chief part of the core of each electromagnet was a rod of steel shafting $7.5 \mathrm{~cm}$. in diameter. This was capped at one end with a disk of soft iron $12.3 \mathrm{~cm}$. in diameter and over $2.5 \mathrm{~cm}$. thick. At the other end the rod was turned down to a cylinder of $3.8 \mathrm{~cm}$. diameter. The bearings were made of brass and bronze, and were 0.5 metre apart, with the coil and contact rings between them and a pulley on the other side of the bearing of smaller diameter. The bearings were firmly screwed to a heavy wooden base, itself bolted to the cement floor. The two magnets were mounted with their axes, as stated above, in the same straight line and the iron disks adjacent and $3 \mathrm{~cm}$. apart.

The magnets were driven with belts by an electric motor at a speed of about 30 revolutions per second. The strength of the field between the poles was about 1200 gausses near the edge, and somewhat greater at the centre.

The small indicating magnet was mounted symmetrically at the centre of a much longer thin brass rod, the two being at right angles. The ends of the brass rod were turned to fit bearings in the caps of a narrow brass tube, which enclosed the rod and its attachments. These included the magnet, the mirror, which was plane, and a small brass vane near the bottom. The tube was mounted in a clamp of brass and wood on the laboratory wall with its axis approximately vertical, parallel to the disks, and in a plane passing through the centres of the disks. The lower part of the tube contained either castor-oil or glycerine; the brass vane, submerged in this fluid, served to damp any motion of the magnet and mirror. A hole was cut in the tube opposite 
the mirror, and over the hole a converging spectacle-lens of 4 metres focal length was fastened with wax.

The optical observations were made by setting with a micrometer eyepiece upon the centre of the image, formed by the mirror and lens, of one of the terminal portions of the incandescent filament of an electric candle. 'The micrometer which carried the lens and cross-hairs of the eyepiece read directly to $0.01 \mathrm{~mm}$. The distance from eyepiece to mirror was greater than 4 metres (see below).

Observations were made with the magnet, always half-way between the pole-faces, in three different positions : a little below the top of the poles, a litile above the bottom, and at the centre of the field. In each case readings were made in sets of four; the first and fourth being made with the magnet on the right rotating clockwise as seen from its right end, the second and third with the motions reversed. The difference, $\mathrm{D}$, obtained by subtracting the mean of the second and third from the mean of the first and fourth, was the immediate quantity sought.

By taking observations in the manner indicated it was sought to eliminate errors arising from the drift of the zero, the relative displacement of the magnets produced by the pull of the belts and the rotation, and the difference between the widths of the image when at rest and in motion.

Some of the most reliable results are given in Table I.

TABLE I.

\begin{tabular}{|c|c|c|c|c|}
\hline $\begin{array}{l}\text { Position of } \\
\text { magnet. }\end{array}$ & $\begin{array}{l}\text { Number } \\
\text { of sets. }\end{array}$ & \multicolumn{2}{|c|}{ D. } & $\begin{array}{c}\text { Distance from } \\
\text { eyepiece to mirror. }\end{array}$ \\
\hline Above & 5 & $\begin{array}{r}\mathrm{mm} . \\
-0.08\end{array}$ & $\begin{array}{r}\mathrm{mm} . \\
\pm 0.01\end{array}$ & $\begin{array}{l}m \\
4 \cdot 1\end{array}$ \\
\hline Above & 5 & -0.09 & \pm 0.02 & $4 \cdot 4$ \\
\hline Centre & 5 & -0.05 & \pm 0.01 & 4.4 \\
\hline Below & 5 & +0.11 & \pm 0.04 & $4 \cdot 4$ \\
\hline Above & 5 & -0.04 & \pm 0.03 & $4 \cdot 4$ \\
\hline Below & 5 & +0.07 & \pm 0.02 & $4 \cdot 4$ \\
\hline
\end{tabular}

The observations in the first four lines were obtained consecutively, as were those in the last two. The + sign indicates a twist of the lines in a clockwise direction as seen from above. The quantity following the \pm is the average absolute departure of the sets in each group from the mean. 
The results obtained with the magnet in the upper and lower positions would at first sight appear to indicate a very slight twist of the lines of induction in the direction to be expected if any entrainment of the lines of induction were actually to occur. Many other observations, similar to those given above, were obtained with the magnet in the upper and lower positions, and the results were always consistent with those given here, except that one group of 5 sets with magnet above gave a positive result $(\mathrm{D}=+0.03 \mathrm{~mm} . \pm 0.02$ $\mathrm{mm}$.). These observations, however, were obtained under unsatisfactory conditions. Nevertheless, in view of the large discrepancies and the systematic errors possible, the only result of which one can be confident is that the change of direction of a line near the edge of the uniform part of the field when the magnets are brought from rest to full speed is not greater than a very minute quantity (the mean from the above table is about $1^{\prime \prime}$ of arc).

In the hope of obtaining still more accurate results, the electromagnets were mounted in new bearings, fitting as closely as practicable ; the bearings were bolted directly to the cement floor, the wooden bases being removed; and the optical arrangement was improved by substituting for the old mirror a new and more accurately ground one by Petitdidier, and by increasing the distance from eyepiece to mirror to 5.4 metres. This distance was kept constant throughout the rest of the work.

The results were of the same character as those obtained before. Thus 5 sets with the magnet in the upper position gave $\mathrm{D}=-0.09 \mathrm{~mm} . \pm 0.02 \mathrm{~mm}$., and 5 sets with the magnet in the lower position gave $\mathrm{D}=+0.16 \mathrm{~mm}$. $\pm 0 \cdot 08 \mathrm{~mm}$.

Mrs. Barnett, to whom I am indebted for assistance throughout the observations described here, having suggested that the distortion of the lines, if any occurred, might be a minimum over the central plane, each line having there a point of inflexion, additional observations were made as close as practicable to one of the pole-faces, but without changing the result. The pole distance of $3 \mathrm{~cm}$., however, was too small to permit of any great shift of the magnet. By boring partially through and remounting the iron disks, the pole distance was therefore increased to $7 \mathrm{~cm}$.; and observations were made with the indicating magnet in three positions, all corresponding in altitude to the upper position of the earlier work, but one close to the left pole, one in the middle as before, and one close to the right pole. The increase of pole distance diminished the intensity to about 800 gausses in the 
central position, and to about 700 gausses in the others. Observations were made somewhat differently from those given above, the motions of the electromagnets not being reversed and the pointings being made with the magnets alternately in slow motion and in rapid motion.

The mean values of the deviations, corresponding to $\frac{1}{2} \mathrm{D}$ in the experiments described above, were $+0.01 \mathrm{~mm}$., $-0.02 \mathrm{~mm}$., and $-0.01 \mathrm{~mm}$. for the three positions, with a mean error between $0.01 \mathrm{~mm}$. and $0.02 \mathrm{~mm}$.

Finally, it was thought worth while to see if any appreciable change in the trend of a line of induction occurred when the electromagnets were both set into rotation in the same direction with the same speed as before-slight as was the probability of obtaining a positive result. For this purpose the indicating magnet was placed outside the region between the poles, though near to one of them, and in such a position that its axis (and the lines of induction through it) made a considerable angle (about $35^{\circ}$ ) with the axis of the field, and the rod supporting the magnet was placed approximately perpendicular to the plane containing the axis of the field and the lines of induction passing through the magnet. Observations made like those just described gave a mean deviation, corresponding to $\frac{1}{2} \mathrm{D}$ in the earlier work, of $+0.03 \mathrm{~mm}$., with a mean error of $0.04 \mathrm{~mm}$. ; indicating therefore that no appreciable bulging out of the lines was produced by the rotation.

For the construction of most of the special apparatus used in the experiments described here, I am indebted to Mr. Arthur Freund, mechanician in the physical laboratory.

The Ohio State University, July 9, 1913.

LXXXIX. The Recombination of Tons made by a Rays. By H. OGDen, Research Scholar in the University of Leeds**.

DRAGG \& KLeEman observed in 1905 that the field $B$ required to obtain the full ionization current in a gas in which a given number of ions were being produced each second was always very much greater if the ions were produced by $\alpha$ rays than if they were produced by $\beta$ rays. They attributed this difference to "Initial Recombination." They supposed that when ions were formed by $\alpha$ rays the separation between the charges was less complete than when they were formed by $\beta$ rays, so that there was a marked tendency for

* Communicated by Prof. W. H. Bragg, F.R.S. 